\title{
Estudo de Caso: Análise Espaço-Temporal do Ribeirão Caladi- nho. Bacia Hidrográfica do Rio Piracicaba, Minas Gerais, para Abastecimento Público
}

\author{
Marluce Teixeira Andrade Queiroz ${ }^{* 1}$, Millor Godoy Sabará2, Carolina Andrade Queiroz ${ }^{3}$, \\ Leonardo Ramos Paes de Lima ${ }^{4}$,Monica Maria Diniz Leão ${ }^{5}$ e Camila Costa Amorim ${ }^{6}$ \\ ${ }^{1}$ Doutoranda na UFMG, Docente do Centro Universitário do Leste de Minas gerais- Unileste-MG \\ ${ }^{2}$ Professor e Pesquisador na UEMG \\ ${ }^{3}$ Engenheira de Segurança em empresa de alimentos, São Paulo, Brasil \\ ${ }^{4}$ Coordenador do Comitê de Ética em Pesquisa do UnilesteMGProf. do Centro Universitário do Leste de Minas \\ Gerais-UnilesteMG , Prof. da Faculdade de Medicina do Vale do Aço-Famevaço \\ ${ }^{5,6}$ Professora Doutorada e Pesquisadora na UFMG
}

\begin{abstract}
Resumo
Os mananciais superficiais estão sujeitos aos danos causados pelas descargas de efluentes domésticos e industriais e pela precariedade dos serviços de coleta e disposição final de resíduos sólidos urbanos. Nesse contexto, a análise qualitativa e quantitativa das águas naturais torna-se essencial na seleção das técnicas de tratamento de água mais adequadas. O objetivo deste trabalho foi à proposiçãa de técnicas de tratamento de água para abastecimento público baseada na caracterização qualitativa das águas do Ribeirão Caladinho, localizado no município de Coronel Fabriciano, Região Metropolitana do Vale do Aço (MG). A relevância dessa pesquisa se traduz no estudo do impacto dos parâmetros físicos, químicos e biológicos de qualidade da água nas unidades componentes de estações de tratamento de água.
\end{abstract}

Palavras-chave: Tratamento de água. Qualidade da água. Impacto ambiental. Ribeirão Caladinho.

\begin{abstract}
The surface waters are subject to damage caused by the discharge of domestic and industrial sewage and by the precariousness of collection and disposal systems of municipal solid waste. In this context, the qualitative and quantitative analysis of natural waters is essential for the selection of water treatment techniques more appropriate. The objective of this study was to propose techniques for water treatment for human consumption based on the qualitative characterization of the water of Caladinho River, located in the city of Coronel Fabriciano Metropolitan Region of the Steel Valley (MG). The relevance of this research is expressed in the study of the impact of physical, chemical and biological water quality parameters in the drinking water utilities.
\end{abstract}

Keywords: Water treatment. Water quality. Environmental impact. Caladinho River. 


\section{Introdução}

$\mathrm{O}$

Brasil é um país rico em recursos hídricos. As bacias hidrográficas nacionais correspondem a $12 \%$ da água doce mundial. No entanto, $20 \%$ da população brasileira (35 milhões de habitantes) não têm acesso à água potável. Tal condição implica em alta vulnerabilidade ambiental agravada pelas condições socioeconômicas, contribuindo para a prevalência de doenças de veiculação hídrica (LIBÂNIO, 2005).

O Outro aspecto desfavorável se relaciona com a deterioração da qualidade das águas superficiais, principalmente em função de atividades antrópicas (uso inadequado do solo, lançamento de efluentes industriais e poluição urbana). A disposição inadequada de resíduos sólidos urbanos e o lançamento de esgotos sanitários diretamente nos corpos d'água constituem práticas comuns nos países em desenvolvimento se destacando como fontes de perigo para os mananciais (BERTOLO et al., 2009).

A má qualidade da água exige a seleção e aplicação de técnicas adequadas de tratamento visando à potabilização. Na concepção das metodologias a serem empregadas em estações de tratamento de água (ETA) devem ser considerados a vazão afluente (capacidade da ETA), os parâmetros físico, químicos e biológicos de qualidade da água bruta (processos e operações unitárias), os custos de implantação e manutenção e a qualificação requerida para os operadores (LIBẨNIO, 2005). Além disso, a legislação ambiental também exige a adoção de mecanismos capazes de favorecer a redução e manejo adequado do lodo gerado nas ETAs (BABATUNDE; ZHAO, 2005).

O objetivo deste estudo foi proposição de técnicas de tratamento para a potabilização das águas do Ribeirão Caladinho, localizado no município de Coronel Fabriciano (MG), em atendimento aos padrões preconizados pela portaria 2.914 do Ministério da Saúde (BRASIL, 2011). A relevância dessa pesquisa se traduz em pro- duzir resultados relacionados com a disseminação do conhecimento pertinente às práticas de descontaminação das águas pluviais.

\section{Fundamentação teórica}

Pádua (2006) reforça que a qualidade da água bruta é o principal parâmetro a ser considerado para definição das técnicas de tratamento que devem ser aplicadas. $\mathrm{O}$ pesquisador ainda pontua que é fundamental que seja considerada a variação sazonal das características do manancial e não apenas valores pontuais, restritos a uma determinada época do ano. Quanto aos aspectos espaciais, espera-se que as bacias cujo solo esteja vulnerável às atividades antrópicas, bem como à jusante de núcleos populacionais, apresentem qualidade pior, principalmente quanto a determinados parâmetros como turbidez e cor.

Com base nas características física, química e microbiológica da água é possível a comparação com sistemas de referências disponíveis em normas e na literatura especializada para a classificação e definição preliminar dos processos e operações unitárias requeridos para a potabilização da água. Ao nível nacional, a NBR 12.216 (ABNT, 1992) fixa as condições exigíveis na elaboração de projetos de ETAs e traz a classificação das águas naturais em quatro tipos (A, B, C ou D) em função das características do manancial (Tabela 1).

O tipo A (Tabela 1) se refere ás águas derivadas de bacias sanitariamente protegidos e que atendem ao padrão de potabilidade, sendo requeridos apenas os processos de desinfecção e estabilização química para adequação dos valores de $\mathrm{pH}$. Um aspecto discordante entre a NBR 12.216 e portaria 2.914 é retratado justamente em relação às águas do tipo A. Segundo a portaria, qualquer tipo de água superficial deverá ser submetida ao processo de filtração, não havendo isenção em nenhuma condição (BRASIL, 2011). Já no caso da NBR 12.216, somente a partir da Classe B é exigida a filtração, embora não seja

Tabela 1 - Tipologia das águas naturais para abastecimento público

\begin{tabular}{|c|c|c|c|c|c|c|c|c|}
\hline \multirow{2}{*}{\multicolumn{2}{|c|}{$\begin{array}{l}\text { Tipo e técnica de } \\
\text { tratamento }\end{array}$}} & \multicolumn{2}{|c|}{$\begin{array}{l}\text { Coliformes totais } \\
\text { (NMP/100 mL) }\end{array}$} & \multicolumn{2}{|c|}{$\begin{array}{c}\mathrm{DBO}_{5} \\
\left(\mathrm{mg} \mathrm{L}^{-1}\right)\end{array}$} & \multirow[t]{2}{*}{ pH } & \multirow{2}{*}{$\begin{array}{l}\text { Cloretos } \\
\left(\mathrm{mg} \mathrm{L}^{-1}\right)\end{array}$} & \multirow{2}{*}{$\begin{array}{c}\text { Fluoretos } \\
\left(\mathrm{mg} \mathrm{L}^{-1}\right)\end{array}$} \\
\hline & & Média & Máximo & édia & Máx & & & \\
\hline A & $\begin{array}{l}\text { Desinfecção e } \\
\text { estabilização do }\end{array}$ & $50 a$ & & $<1,5$ & 1 a 3 & & $<50$ & $<1,5$ \\
\hline B & $\begin{array}{l}\text { Filtração, desinfecção } \\
\text { e estabilização do pH }\end{array}$ & $100 \mathrm{a}$ & $>5.000^{(\mathrm{b})}$ & 1,5 a 2,5 & 3 a 4 & 5 a 9 & 50 & 1,5 \\
\hline 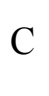 & $\begin{array}{l}\text { Tratamento } \\
\text { convencional }\end{array}$ & \multicolumn{2}{|c|}{5.000 a $20.000>20.000^{(\mathrm{c})}$} & 2,5 a 4,0 & 4 a 6 & 5 a 9 & 250 & $>3,0$ \\
\hline D & Tratamento especial & $>20.000$ & - & $>4,0$ & $>6$ & $\begin{array}{l}3,8 \mathrm{a} \\
10,3\end{array}$ & $>600$ & - \\
\hline
\end{tabular}

NMP: Número mais provável; (a) em menos de $5 \%$ das amostras; (b) em menos de 20 \% das amostras; (c) em menos de $5 \%$ das amostras.

Fonte: ABNT (1992). 
Tabela 2 - Técnicas de tratamento em função das características das águas naturais.

\begin{tabular}{lccccc}
\hline & \multicolumn{5}{c}{ Técnica de tratamento } \\
\cline { 2 - 5 } \multicolumn{1}{c}{ Parâmetro } & Convencional & $\begin{array}{c}\text { Dupla } \\
\text { filtração }\end{array}$ & $\begin{array}{c}\text { Filtração } \\
\text { direta }\end{array}$ & $\begin{array}{c}\text { Filtração } \\
\text { lenta(a) }\end{array}$ & $\begin{array}{c}\text { Filtração } \\
\text { direta } \\
\text { em linha }\end{array}$ \\
\hline Turbidez (uT) & $<3.000$ & $<50$ & $<20$ & $<10$ & $<5$ \\
Cor aparente (uC) & $<1.000$ & $<50$ & $<20$ & $<20$ & $<15$ \\
Escherichia coli & $<10^{6}$ & $<10^{3}$ & $<10^{3}$ & $<10^{3}$ & $<100$ \\
(NMP/100 mL) & $<10^{5}$ & $<5 \cdot 10^{3}$ & $<10^{3}$ & $<250$ & $<100$ \\
Algas (UPA/mL) & & & & & \\
\hline
\end{tabular}

(a) Sem o emprego de pré-filtros.

Fonte: Kawamura (2000, apud LIBÂNIO, 2005).

necessária a inclusão da coagulação química.

As águas do tipo C (Tabela 1) deverão ser submetidas ao tratamento convencional, incluindo as etapas de coagulação, floculação, decantação ou flotação, filtração, desinfecção, correção de pH e fluoretação. Por fim, na Classe D são encontradas as águas provenientes de mananciais não protegidos e que requerem tratamentos especiais para atender ao padrão de potabilidade. Alguns exemplos de processos específicos para a remoção de poluentes são: uso da cal-sodada, zeólitos ou osmose inversa para remoção da dureza; a correção da acidez através de leito de pedra calcária; e a remoção da cor e odor com carvão ativado, filtração lenta ou aeração (HELLER, 2006).

Outros valores de referência para a seleção de técnicas de tratamento de água foram propostos por Kawamura (2000, apud LIBÂNIO, 2005) e apresentados na Tabela 2. Observa-se que, assim como a NBR 12.216, o número de parâmetros avaliados é pequeno, sendo pouco representativo da qualidade da água. Apesar disso, o conjunto desses parâmetros serve de guia para nortear os estudos preliminares de seleção de técnicas de tratamento bem como ensaios de tratabilidade.

Ouras faixas de valores para os parâmetros de qualidade da água bruta que podem ser utilizados como referência foram propostas por Sabogal-Paz (2007) e mostradas na Tabela 3. A autora apresenta os valores máximos associados à proporção das amostras que devem estar abaixo dos respectivos limites. Tal abordagem se mostra mais abrangente, uma vez que considera, em parte, a própria variabilidade inerente à distribuição dos valores dos parâmetros monitorados. Além disso, admite certa robustez das técnicas de tratamento para variações atípicas na qualidade da água que de fato podem ocorrer.

Um dos maiores desafios para engenheiros e técnicos responsáveis pelo planejamento e operação de sistemas de aproveitamento de recursos hídricos, é fornecer quantidades adequadas de água com qualidade apropriada e no momento certo para atender aos seus múltiplos usos. Embora do ponto de vista teórico não haja grande dificuldade de se integrar o gerenciamento de quantidade e qualidade, na prática esta interação é raramente alcançada, representando um grande obstáculo para a

Tabela 3 - Técnicas de tratamento de água associada às características da água bruta.

\begin{tabular}{ccccccc}
\hline \multirow{2}{*}{ Parâmetro } & \multicolumn{5}{c}{ Técnica de tratamento } \\
\cline { 2 - 6 } & FDD & FDA & DF & FiME & FF & CC \\
\hline \multirow{2}{*}{ Turbidez } & $100 \% \leq 50$ & $100 \% \leq 50$ & $100 \% \leq 200$ & $100 \% \leq 100$ & $100 \% \leq 100$ & \\
(uT) & $95 \% \leq 30$ & $95 \% \leq 30$ & $95 \% \leq 150$ & $95 \% \leq 50$ & $95 \% \leq 60$ & $100 \% \leq 500$ \\
& $90 \% \leq 20$ & $90 \% \leq 20$ & $90 \% \leq 100$ & $90 \% \leq 30$ & $90 \% \leq 40$ & \\
Cor verdadeira & $100 \% \leq 50$ & $100 \% \leq 50$ & $100 \% \leq 100$ & $100 \% \leq 20$ & $100 \% \leq 200$ & \\
(uC) & $95 \% \leq 25$ & $95 \% \leq 25$ & $95 \% \leq 75$ & $95 \% \leq 15$ & $95 \% \leq 100$ & $100 \% \leq 250$ \\
& $90 \% \leq 20$ & $90 \% \leq 20$ & $90 \% \leq 50$ & $90 \% \leq 10$ & $90 \% \leq 50$ & \\
Coliformes totais & $100 \% \leq 2.500$ & $100 \% \leq 2.500$ & $100 \% \leq 5.000$ & $100 \% \leq 20.000$ & $100 \% \leq 5.000$ & \\
(NMP/100 mL) & $95 \% \leq 1.500$ & $95 \% \leq 1.500$ & $95 \% \leq 2.500$ & $95 \% \leq 15.000$ & $95 \% \leq 2.500$ & $100 \% \leq 20.000$ \\
& $90 \% \leq 1.000$ & $90 \% \leq 1.000$ & $90 \% \leq 1.500$ & $90 \% \leq 10.000$ & $90 \% \leq 1.500$ & \\
\hline \multirow{2}{*}{ Escherichia coli } & $100 \% \leq 1.000$ & $100 \% \leq 1.000$ & $100 \% \leq 1.500$ & $100 \% \leq 10.000$ & $100 \% \leq 1.500$ & \\
(NMP/100 mL) & $95 \% \leq 750$ & $95 \% \leq 750$ & $95 \% \leq 1.000$ & $95 \% \leq 5.000$ & $95 \% \leq 1.000$ & $100 \% \leq 10.000$ \\
& $90 \% \leq 500$ & $90 \% \leq 500$ & $90 \% \leq 500$ & $90 \% \leq 1.000$ & $90 \% \leq 500$ & \\
\hline
\end{tabular}

As porcentagens se referem à fração do total de amostras realizadas para o referido parâmetro; FDD: filtração direta descendente; FDA: filtração direta ascendente; DF: dupla filtração; FF: floto-filtração; FiME: filtração em múltiplas etapas; CC: ciclo completo.

Fonte: Sabogal-Paz (2007). 
operação eficiente de sistemas e a utilização racional dos recursos hídricos (AZEVEDO et al., 1998). Desta forma a escolha adequada dos processos de tratamento a ser empregado em cada caso é de fundamental importância para a manutenção da integridade da saúde da população atendida como também da manutenção da menor relação custo benefício do sistema (SABOGAL E DI BERNARDO, 2007).

\section{Materiais e métodos}

\section{1 área de estudo}

O município de Coronel Fabriciano possui área total de $220 \mathrm{~km}^{2}$ e abriga cerca de 104.000 habitantes, 97,8\% na zona urbana (IBGE, 2012). Coronel Fabriciano integra a Região Metropolitana do Vale do Aço (RMVA) (Figura 1) apresentando uma economia predominante industrial, com a presença de siderurgias e de curtumes, dentre outras fontes poluidoras estacionárias (MINAS GERAIS, 2012). O Ribeirão Caladinho possui $12 \mathrm{~km}$ de extensão e está localizado integralmente no município de Coronel Fabriciano, passando pelo centro do mesmo e desaguando no Rio Piracicaba, um dos principais cursos d'água da Bacia Hidrográfica do Rio Doce.

Selecionaram-se três pontos de amostragem no Ribeirão Caladinho: nascente $\left(\mathrm{P}_{1}\right)$, região central $\left(\mathrm{P}_{2}\right)$ e foz $\left(\mathrm{P}_{3}\right)$. Foram realizadas dez campanhas para a coleta de amostras compostas, com frequência mensal, no período de julho de 2010 a agosto de 2011, com o intuito de abranger os períodos seco e chuvoso. Cabe destacar que no ponto $\mathrm{P}_{2}$ há um reservatório de acumulação objetivando garantir o abastecimento público, o que contribui para formação de um ambiente lêntico nesse trecho. As coordenadas dos pontos de amostragem são mostradas na Tabela 4 e a localização na Figura 2.

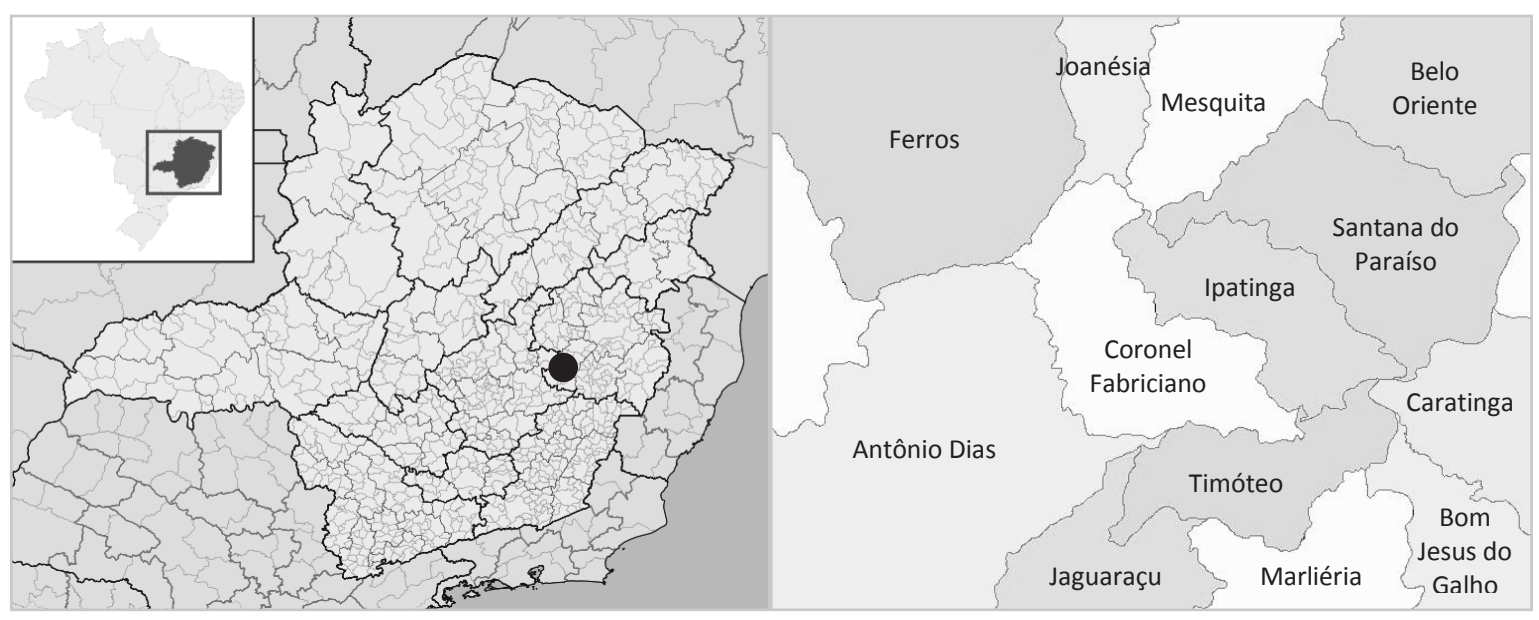

Figura 1 - Localização do município de Coronel Fabriciano. Fonte: adaptado de IGA (2012).

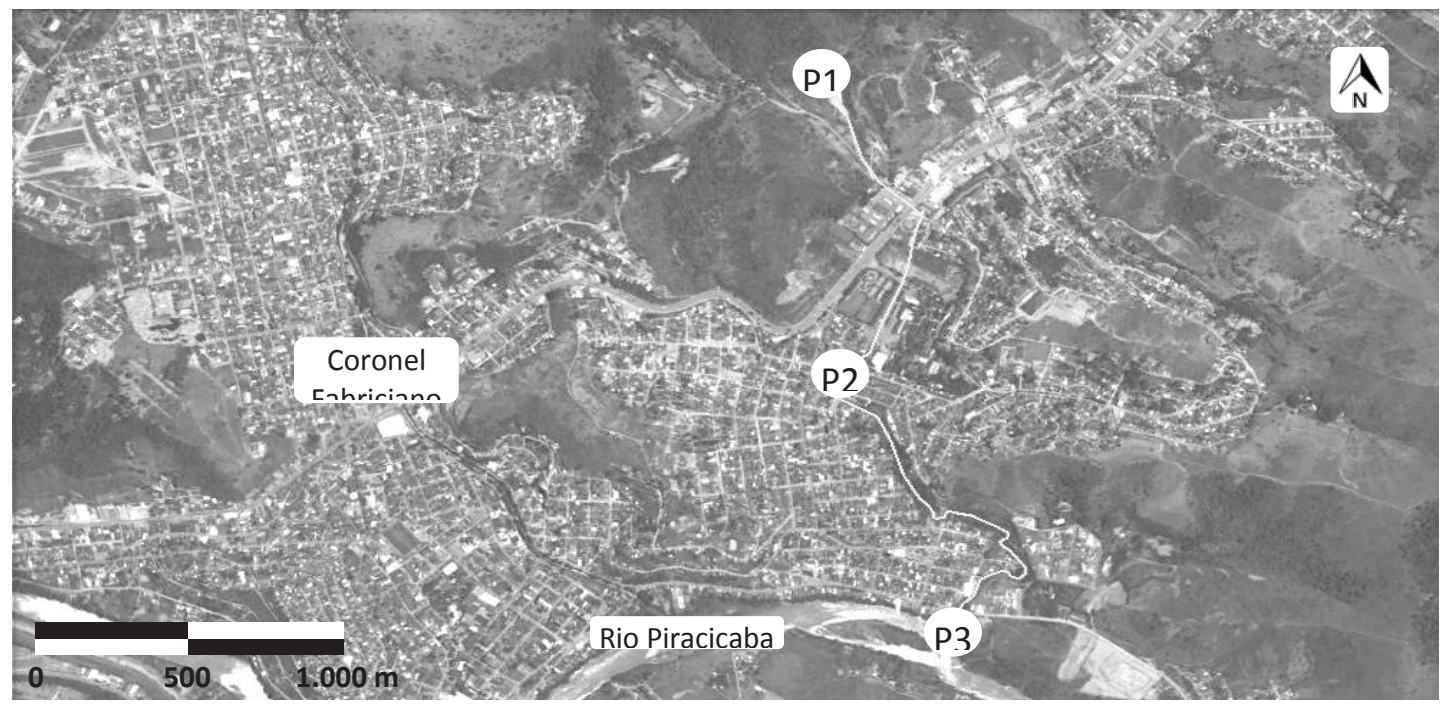

Figura 2 - Localização dos pontos de amostragem (P1, P2 e P3). 
Tabela 4 - Coordenadas dos pontos de amostragem.

\begin{tabular}{|c|c|}
\hline Ponto de coleta & Coordenadas e elevação \\
\hline P1 - Nascente & S 19³0'25,3'” - O 42³6’47,3'’ - Elevação: $268 \mathrm{~m}$ \\
\hline P2 - Região central & S 19³1'02,9'” - O 42³6'43,3'” - Elevação: $265 \mathrm{~m}$ \\
\hline $\mathrm{P} 3-\mathrm{Foz}$ & S 19³1'32,3'" - O 42³6'31,5'” - Elevação: $260 \mathrm{~m}$ \\
\hline
\end{tabular}

\subsection{Procedimentos analíticos}

As amostras de água foram coletadas em recipientes de vidro de cor âmbar esterilizados. Imediatamente antes da coleta os recipientes foram ambientados três vezes com as águas em estudo. Em seguida, os frascos foram mergulhados no rio e virados lentamente no sentido contra a corrente até serem completamente preenchidos. Os procedimentos de coleta ocorreram com luvas para reduzir o risco de contaminação. As amostras foram acondicionadas em caixa de isopor contendo blocos de gelo durante todo o período da campanha. As subamostras para cada análise ou conjunto destas foram separadas em frascos de polietileno, que, por sua vez, foram identificados e mantidos refrigerados à $4^{\circ} \mathrm{C}$ (APHA, 2005).

Os parâmetros mensurados são mostrados na Tabela 5. As análises realizadas seguiram os procedimentos propostos pela American Public Health Association (APHA, 2005).

Tabela 5 - Parâmetros monitorados e métodos de análise.

\begin{tabular}{|l|l|c|c|}
\hline \multicolumn{1}{|c|}{ Parâmetro } & \multicolumn{1}{|c|}{ Método } & $\begin{array}{c}\text { Standard } \\
\text { Methods }\end{array}$ & $\begin{array}{c}\text { Limite de } \\
\text { detecção }\end{array}$ \\
\hline CE & Condutimetria & $2510 \mathrm{~B}$ & $1 \mathrm{mS} . \mathrm{cm}^{-1}$ \\
\hline $\begin{array}{l}\text { Coliforme } \\
\text { termotolerante }\end{array}$ & Tubos múltiplos & $9221 \mathrm{E}$ & $\begin{array}{c}2 \mathrm{NMP} / 100 \\
\mathrm{~mL}\end{array}$ \\
\hline $\begin{array}{l}\text { Coliformes } \\
\text { totais }\end{array}$ & Tubos múltiplos & $9223 \mathrm{~B}$ & $\begin{array}{c}2 \mathrm{NMP} / 100 \\
\mathrm{~mL}\end{array}$ \\
\hline Cor verdadeira & $\begin{array}{l}\text { Método do } \\
\text { cloroplatinato de } \\
\text { potássio }\end{array}$ & $\begin{array}{c}2120 \mathrm{C} . \\
2-3\end{array}$ & $5 \mathrm{uHz}$ \\
\hline DBO & $\begin{array}{l}\text { Diluição e } \\
\text { incubação por } \\
5 \text { dias }\end{array}$ & $5210 \mathrm{~B}$ & $2 \mathrm{mg} . \mathrm{L}^{-1}$ \\
\hline DQO & $\begin{array}{l}\text { Colorimétrico, } \\
\text { refluxo fechado }\end{array}$ & $5220 \mathrm{D}$ & $4 \mathrm{mg} . \mathrm{L}^{-1}$ \\
\hline $\begin{array}{l}\text { Oxigênio } \\
\text { dissolvido }\end{array}$ & Potenciometria & $4500 \mathrm{O}-\mathrm{G}$ & $0,1 \mathrm{mg} . \mathrm{L}^{-1}$ \\
\hline pH & Potenciometria & $5520 \mathrm{~B}$ & $\begin{array}{c}\mathrm{Não} \mathrm{se} \\
\text { aplica }\end{array}$ \\
\hline STD & $\begin{array}{l}\text { Gravimétrico, } \\
\text { secagem a } \\
103-105^{\circ} \mathrm{C}\end{array}$ & $2540 \mathrm{C}$ & $1 \mathrm{mg} . \mathrm{L}^{-1}$ \\
\hline Temperatura & Nefelometria & $2130 \mathrm{~B}$ & $1 \mathrm{mg} . \mathrm{L}^{-1}$ \\
\hline Turbidez
\end{tabular}

Fonte: APHA (2005).

\subsection{Tratamento dos dados}

Inicialmente, os parâmetros monitorados passaram por análise descritiva. Em seguida foram feitos testes estatísticos com o intuito de verificar a existência de diferenças significativas entre os valores dos parâmetros em função dos fatores espaciais (pontos ao longo do Ribeirão Caladinho) e temporais (períodos seco e chuvoso) e correlação entre os mesmos. O tratamento estatístico dos dados foi feito utilizando-se o programa Statoft Statistica ${ }^{\circledR}$, versão 8.0 (STATSOFT, 2007), e adotou-se o nível de significância de 5\% em todos os testes.

Para verificar se os parâmetros sofrem modificações significativas ao longo do curso d'água, as três amostras retiradas de cada um dos pontos (nascente, região central e foz) foram comparadas entre si. Este procedimento foi repetido para cada um dos 11 parâmetros. Na ausência de informações acerca da distribuição de probabilidade dos dados, foi empregado o teste Friedman (não paramétrico). Para avaliar a variação dos parâmetros entre os períodos seco (junho a setembro) e chuvoso (outubro a janeiro) foi utilizado o teste Mann-Whitney para comparação de uma total de 33 conjuntos de dados (11 parâmetros em três pontos de coleta). A correlação foi determinada pelo coeficiente de Spearman.

Por fim, os parâmetros foram comparados com os valores de referência (Tabelas 1, 2 e 3) visando à classificação das águas do Ribeirão Caladinho e a seleção das técnicas de tratamento. Além disso, foram comparados com o disposto na resolução CONAMA 357 (BRASIL, 2005). De acordo com a resolução, as águas doces superficiais que ainda não passaram pelo processo de enquadramento são consideradas Classe 2, destinadas ao abastecimento para consumo humano, proteção das comunidades aquáticas e recreação de contato primário.

\section{Resultados e discussão}

\subsection{Caracterização do Ribeirão Caladinho}

A estatística descritiva dos parâmetros monitorados é mostrada na Tabela 6. Quando os limites de detecção de coliformes totais e termotolerantes foram ultrapassados, adotou-se o valor máximo (2.420 NMP/100 mL).

De acordo com as informações levantadas nos pontos de amostragem (Tabela 7), o Ribeirão Caladinho se encontra em uma bacia sanitariamente desprotegida e sob forte influência das atividades antrópicas. $\mathrm{O}$ distrito 
Tabela 6 - Estatísticas descritivas dos parâmetros monitoradas.

\begin{tabular}{|c|c|c|c|c|c|c|c|c|c|}
\hline \multirow{2}{*}{ Parâmetro } & \multirow{2}{*}{ Ponto $^{(a)}$} & \multirow{2}{*}{$\begin{array}{l}\text { Méd. } \\
\text { arit. }\end{array}$} & \multirow{2}{*}{$\begin{array}{l}\text { Méd. } \\
\text { geom. }\end{array}$} & \multirow{2}{*}{ Mediana } & \multirow{2}{*}{ Mín. } & \multicolumn{2}{|c|}{ Percentis } & \multirow{2}{*}{ Máx. } & \multirow{2}{*}{ CV $(\%)$} \\
\hline & & & & & & $25 \%$ & $75 \%$ & & \\
\hline \multirow{3}{*}{$\begin{array}{c}\text { Coliformes } \\
\text { termotolerantes } \\
(\mathrm{NMP} / 100 \mathrm{~mL})\end{array}$} & $\mathrm{P} 1$ & 97 & 72 & 49 & 32 & 38 & 154 & 275 & 85 \\
\hline & $\mathrm{P} 2$ & 795 & 750 & 908 & 355 & 577 & 1.011 & 1.011 & 32 \\
\hline & P3 & 1.115 & 1.056 & 1.011 & 675 & 1.011 & 1.011 & $2.420^{(\mathrm{b})}$ & 42 \\
\hline \multirow{3}{*}{$\begin{array}{l}\text { Coliformes totais } \\
(\mathrm{NMP} / 100 \mathrm{~mL})\end{array}$} & $\mathrm{P} 1$ & 139 & 93 & 60 & 35 & 45 & 286 & 385 & 94 \\
\hline & $\mathrm{P} 2$ & 1.513 & 1.307 & 1.064 & 410 & 997 & $2.420\left(^{\text {b) }}\right.$ & $2.420^{(\mathrm{b})}$ & 53 \\
\hline & $\mathrm{P} 3$ & 2.116 & 1.983 & $2.420^{(\mathrm{b})}$ & 789 & $2.420^{(\mathrm{b})}$ & $2.420^{(\mathrm{b})}$ & $2.420^{(\mathrm{b})}$ & 30 \\
\hline \multirow{3}{*}{$\begin{array}{l}\text { Condutividade } \\
\text { elétrica }\left(\mu \mathrm{S} \mathrm{cm}^{-1}\right)\end{array}$} & $\mathrm{P} 1$ & 39 & 37 & 40 & 17 & 35 & 43 & 65 & 31 \\
\hline & $\mathrm{P} 2$ & 194 & 174 & 209 & 43 & 154 & 233 & 342 & 41 \\
\hline & P3 & 250 & 226 & 241 & 68 & 180 & 306 & 405 & 41 \\
\hline \multirow{3}{*}{ Cor verdadeira (uH) } & $\mathrm{P} 1$ & 67,2 & 66,2 & 63,2 & 50,5 & 58,8 & 78,0 & 87,0 & 18 \\
\hline & $\mathrm{P} 2$ & 97,7 & 94,4 & 98,2 & 52,4 & 78,7 & 124,0 & 129,0 & 26 \\
\hline & $\mathrm{P} 3$ & 113,3 & 109,0 & 104,9 & 76,0 & 82,0 & 137,0 & 160,0 & 29 \\
\hline \multirow{3}{*}{$\mathrm{DBO}_{5}\left(\mathrm{mg} \mathrm{L}^{-1}\right)$} & $\mathrm{P} 1$ & 26 & 24 & 27 & 14 & 16 & 35 & 41 & 38 \\
\hline & P2 & 59 & 56 & 56 & 34 & 45 & 75 & 89 & 32 \\
\hline & P3 & 73 & 71 & 75 & 44 & 57 & 88 & 95 & 24 \\
\hline \multirow{3}{*}{ DQO $\left(\mathrm{mg} \mathrm{L}^{-1}\right)$} & $\mathrm{P} 1$ & 44 & 41 & 50 & 23 & 27 & 57 & 69 & 38 \\
\hline & $\mathrm{P} 2$ & 185 & 171 & 159 & 98 & 128 & 263 & 289 & 40 \\
\hline & $\mathrm{P} 3$ & 245 & 234 & 218 & 128 & 195 & 319 & 343 & 31 \\
\hline \multirow{3}{*}{$\begin{array}{l}\text { Oxigênio dissolvido } \\
\qquad\left(\mathrm{mg} \mathrm{L}^{-1}\right)\end{array}$} & $\mathrm{P} 1$ & 7 & 6 & 7 & 4 & 6 & 7 & 8 & 19 \\
\hline & $\mathrm{P} 2$ & 3 & 2 & 2 & 1 & 2 & 3 & 4 & 45 \\
\hline & $\mathrm{P} 3$ & 2 & 1 & 2 & 1 & 1 & 2 & 4 & 58 \\
\hline \multirow{3}{*}{$\mathrm{pH}$} & $\mathrm{P} 1$ & 6,8 & 6,7 & 6,9 & 5,5 & 6,4 & 7,3 & 7,4 & 9 \\
\hline & $\mathrm{P} 2$ & 7,7 & 7,7 & 7,9 & 6,6 & 7,2 & 8,2 & 8,5 & 8 \\
\hline & P3 & 8,1 & 8,1 & 8,2 & 7,1 & 7,8 & 8,5 & 8,6 & 6 \\
\hline \multirow{3}{*}{$\begin{array}{c}\text { Sólidos totais } \\
\text { dissolvidos }\left(\mathrm{mg} \mathrm{L}^{-1}\right)\end{array}$} & $\mathrm{P} 1$ & 70 & 65 & 68 & 20 & 62 & 83 & 119 & 35 \\
\hline & $\mathrm{P} 2$ & 281 & 262 & 290 & 101 & 207 & 358 & 392 & 34 \\
\hline & P3 & 341 & 325 & 334 & 165 & 279 & 412 & 495 & 31 \\
\hline \multirow{3}{*}{$\begin{array}{l}\text { Temperatura da } \\
\text { água }\left({ }^{\circ} \mathrm{C}\right)\end{array}$} & $\mathrm{P} 1$ & 22 & 22 & 22 & 20 & 20 & 23 & 25 & 8 \\
\hline & $\mathrm{P} 2$ & 22 & 22 & 22 & 21 & 21 & 23 & 25 & 5 \\
\hline & P3 & 23 & 23 & 23 & 21 & 21 & 24 & 24 & 6 \\
\hline \multirow{3}{*}{ Turbidez (uT) } & $\mathrm{P} 1$ & 44,9 & 41,6 & 39,9 & 23,9 & 29,5 & 65,0 & 73,0 & 41 \\
\hline & $\mathrm{P} 2$ & 81,9 & 78,2 & 86,5 & 31,9 & 75,8 & 97,0 & 102,0 & 27 \\
\hline & $\mathrm{P} 3$ & 97,9 & 94,4 & 95,7 & 57,8 & 84,5 & 102,0 & 154,0 & 28 \\
\hline
\end{tabular}

(a) Tamanho das amostras = 10; (b) Limite de detecção. (b) ultrapassados os limites de detecção de coliformes totais e termotolerantes, adotou-se o valor máximo de $2.420 \mathrm{NMP} / 100 \mathrm{~mL}$.

industrial de Coronel Fabriciano se localiza na região oeste e ocupa uma área de $183.000 \mathrm{~m}^{2}$, abarcando 38 empresas de diferentes segmentos econômicos (MINAS GERAIS, 2012) tornando curso d'água sujeito à descarga de efluentes bastante distintos.

Os achados indicaram a necessidade quanto às ações de proteção do manancial, principalmente em relação à nascente (P1). As atividades poluidoras identificadas nos trechos à montante dos pontos de amostragem (Tabela 7) são consonantes com o a pior qualidade da água observada nos pontos da região central (P2) e foz (P3) (Tabela 6). 
Tabela 7 - Observações feitas nos pontos de amostragem.

\begin{tabular}{|c|c|}
\hline $\begin{array}{c}\text { Ponto de } \\
\text { coleta }\end{array}$ & Observações \\
\hline $\begin{array}{c}\text { P1 - Nas- } \\
\text { cente }\end{array}$ & $\begin{array}{c}\text { Evidências de pastio de animais (bovinos, } \\
\text { suínos, eqüinos, entre outros), disposição } \\
\text { inadequada de resíduos sólidos, mata ciliar } \\
\text { degradada próximo da nascente. }\end{array}$ \\
\hline $\begin{array}{c}\text { P2 - Re- } \\
\text { gião cen- } \\
\text { tral }\end{array}$ & $\begin{array}{c}\text { Disposição inadequada de resíduos sólidos do- } \\
\text { miciliares, construções precárias, irrigação } \\
\text { de culturas arbóreas, erosão nas margens } \\
\text { do ribeirão, crianças em contato direto } \\
\text { com a água. }\end{array}$ \\
\hline $\begin{array}{c}\text { P3 - Foz } \\
\text { beposição inadequada de resíduos sólidos ur- } \\
\text { banos, dessedentação de animais, crianças } \\
\text { em contato direto com a água. }\end{array}$ \\
\hline
\end{tabular}

\subsection{Influência dos fatores espacial e temporal e correlação}

De acordo com o teste Friedman, os valores de todos os parâmetros tem variação significativa (valor $\mathrm{p}<$ 0,001 ) entre os pontos de amostragem, com exceção da temperatura da água (valor $\mathrm{p}=0,332$ ). Pela Figura 3 é clara a deterioração da qualidade da água à medida que
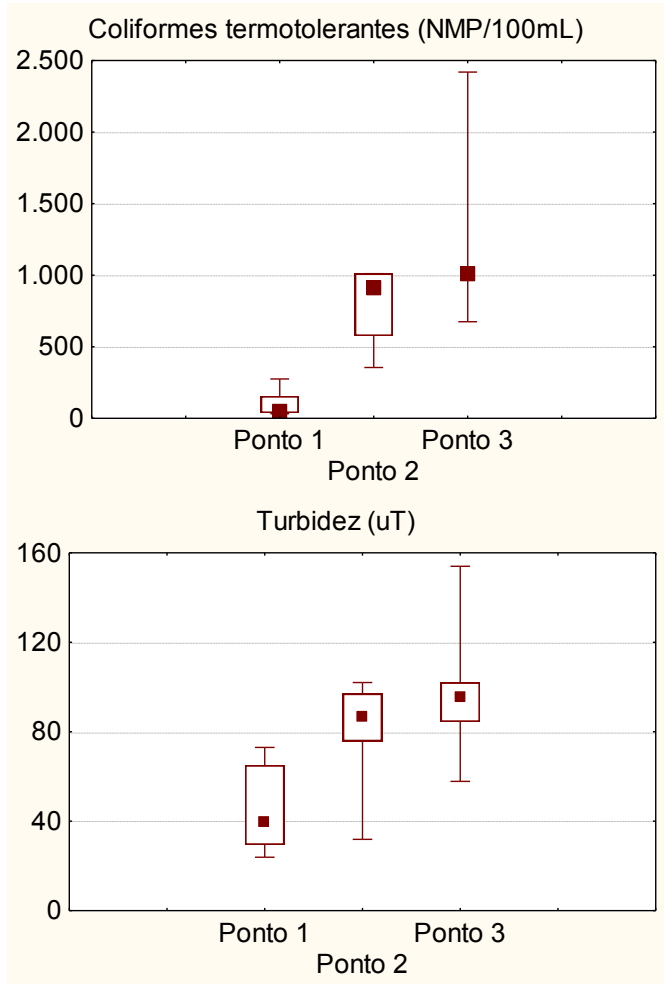

a distância da nascente aumenta. Assim, recomenda-se que a captação seja feita no ponto mais próximo da nascente, onde a qualidade da água é melhor.Figura 3 - Box-plot dos parâmetros $\mathrm{DBO}_{5}$, coliformes termotolerantes, turbidez e cor verdadeira para cada ponto de amostragem.

Dos 33 conjuntos de dados avaliados (11 parâmetros em três pontos de coleta) apenas três apresentaram variação significativa entre os períodos seco e chuvoso: pH em P2 (valor $\mathrm{p}=0,016$ ), condutividade elétrica em $\mathrm{P}_{1}$ (valor $\left.\mathrm{p}=0,047\right)$ e sólidos totais dissolvidos em P2 (valor $\mathrm{p}=0,047$ ) (Figura 4). Logo, pode-se afirmar que a qualidade da água do Ribeirão Caladinho não sofre variação entre os períodos seco e chuvoso. Tal resultado é de suma importância na definição da técnica de tratamento, uma vez que esta deve ser capaz de produzir água potável mesmo nas estações do ano em que as características da água bruta se mostrem mais desfavoráveis e de menor tratabilidade, situação verificada, em geral, no período chuvoso.

Verificou-se a existência de correlação significativa entre todos os parâmetros avaliados, exceto para a temperatura da água (Tabela 8). Este último não se correlacionou com os parâmetros coliformes totais, coliformes termotolerantes, condutividade elétrica, oxigênio dissolvido, $\mathrm{pH}$ e sólidos dissolvidos totais. Os maiores coeficientes de correlação observados foram: entre turbidez e cor verdadeira $(0,982)$, ente $\mathrm{DBO}_{5}$ e
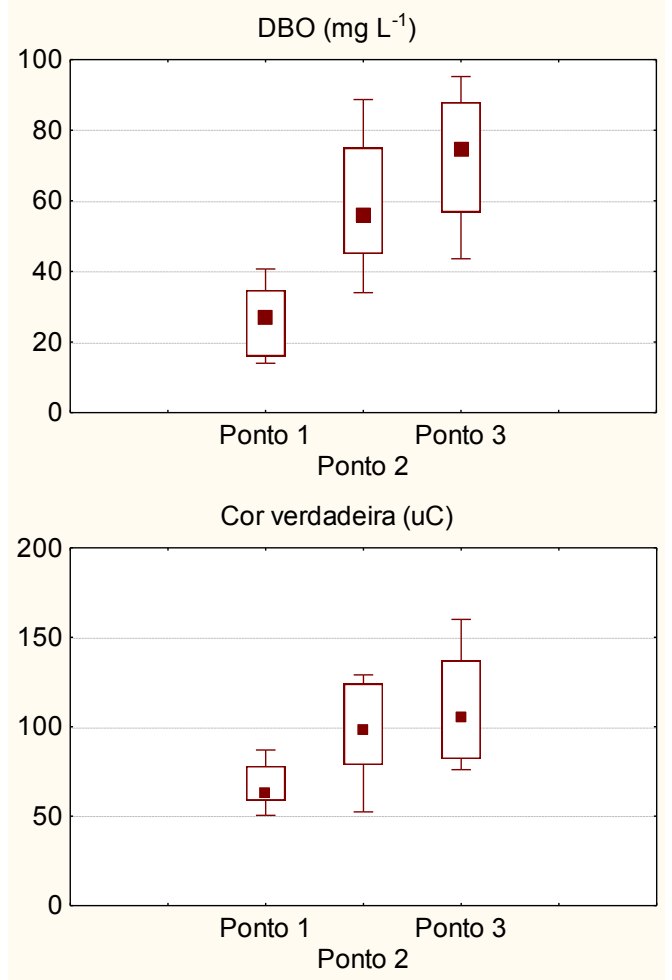

I valores mínimo e máximo

Figura 3 - Box-plot dos parâmetros DBO5, coliformes termotolerantes, turbidez e cor verdadeira para cada ponto de amostragem. 

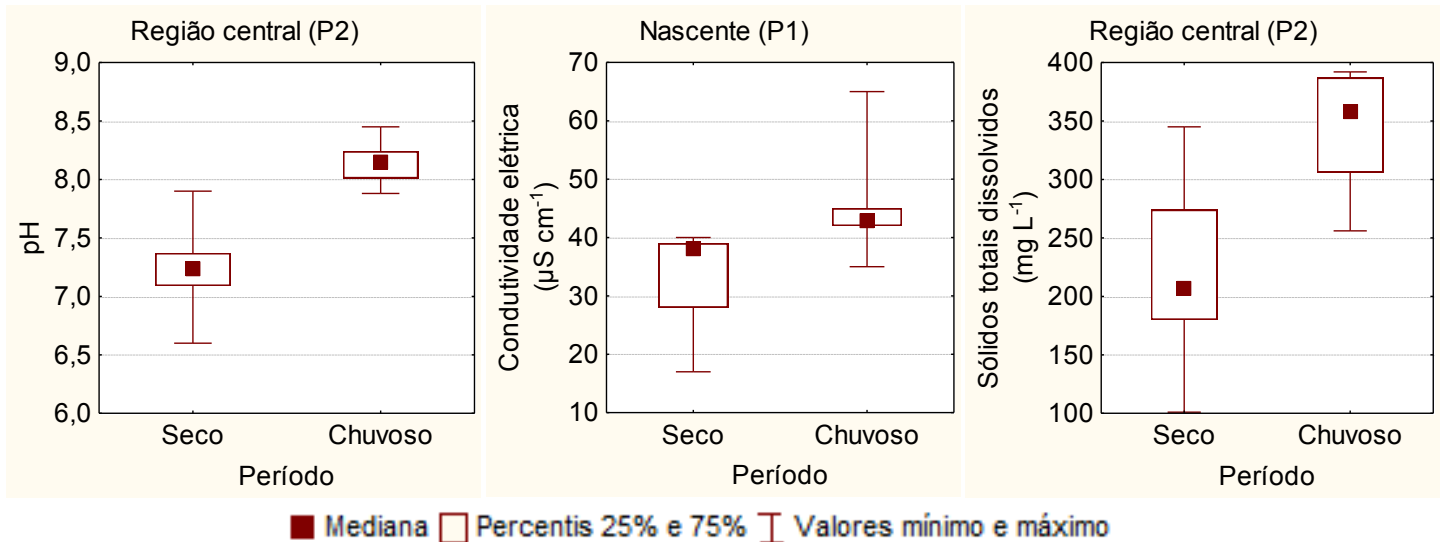

Figura 4 - Box-plot dos parâmetros $\mathrm{pH}$, condutividade elétrica e sólidos totais dissolvidos para os períodos seco e chuvoso.

Tabela 8 - Coeficientes de correlação de Spearman

\begin{tabular}{lcccccccccc}
\hline \multicolumn{1}{c}{ Parâmetro } & (1) & (2) & (3) & (4) & (5) & (6) & (7) & (8) & (9) & (10) \\
\hline (1) Coliformes termotolerantes & - & & & & & & & & & \\
(2) Coliformes totais & 0,940 & - & & & & & & & & \\
(3) Condutividade elétrica & 0,734 & 0,734 & - & & & & & & & \\
(4) $\mathrm{Cor}$ & 0,749 & 0,783 & 0,687 & - & & & & & & \\
(5) $\mathrm{DBO}_{5}$ & 0,762 & 0,807 & 0,607 & 0,773 & - & & & & & \\
(6) $\mathrm{DQO}$ & 0,820 & 0,846 & 0,665 & 0,826 & 0,981 & - & & & & \\
(7) $\mathrm{O} 2$ & $-0,824$ & $-0,867$ & $-0,669$ & $-0,762$ & $-0,819$ & $-0,860$ & - & & & \\
(8) $\mathrm{pH}$ & 0,691 & 0,664 & 0,802 & 0,499 & 0,466 & 0,507 & $-0,429$ & - & & \\
(9) Sólidos totais dissolvidos & 0,834 & 0,830 & 0,824 & 0,742 & 0,747 & 0,795 & $-0,689$ & 0,711 & - & \\
(10) Temperatura da água & $0,272^{*}$ & $0,278^{*}$ & $0,173^{*}$ & 0,536 & 0,416 & 0,420 & $-0,262^{*}$ & $0,182^{*}$ & $0,286^{*}$ & - \\
(11) Turbidez & 0,819 & 0,836 & 0,718 & 0,982 & 0,792 & 0,852 & $-0,768$ & 0,568 & 0,779 & 0,498 \\
\hline
\end{tabular}

* Correlação NÃO significativa ao nível de 5\% de significância.

DQO $(0,981)$ e entre coliformes totais e coliformes termotolerantes $(0,940)$. O estudo das correlações permite a exclusão de certos parâmetros que apresentam forte interdependência com outros, simplificando o monitoramento. Tomando como exemplo a $\mathrm{DBO}_{5}$ e a DQO, como há forte dependência entre os mesmos, poderia se optar pelo monitoramento de apenas um, nesse caso, da DQO, de mais fácil determinação.

\subsection{Seleção da técnica de tratamento}

Os resultados (Tabela 1) permitiram a classificação do Ribeirão Caladinho manancial Tipo D segundo a NBR 12.216 (ABNT, 1992) em função da $\mathrm{DBO}_{5^{\prime}}$ que atingiu valores médios e máximos superiores respectivamente a 4 e 6. Para este tipo de água, a norma sugere processos especiais de tratamento para o atendimento ao padrão de potabilidade, sendo composto por coagulação, seguido ou não de decantação, filtração rápida, desinfecção, correção do $\mathrm{pH}$ e tratamento complementar conforme a impureza a ser removida.

Apesar da indicação das operações unitárias e processos requeridos para as águas do Ribeirão Caladinho, a norma não define com clareza quais as alternativas para o tratamento complementar. Supõe-se que tal escolha deve passar por estudo mais detalhado e abrangendo maior número de parâmetros. Ressalta-se que não foram avaliadas as concentrações de cloretos fluoretos.

Pela Tabela 2, proposta por Kawamura (2000, apud LIBÂNIO, 2005), os elevados valores de turbidez e cor conduzem à seleção do tratamento convencional, assim como a NBR 12.216 (ABNT, 1992). Nesse caso, a falta de dados referentes à Escherichia coli e algas também dificulta a seleção da técnica. Entretanto, como a técnica selecionada pode ser considerada relativamente a mais robusta, a magnitude da concentração desses dois parâmetros tem menos importância de acordo com o método de seleção sugerido pelo autor.

Os valores levantados por Sabogal-Paz (2007) corroboram com os da NBR 12.216 (ABNT, 1992) e de Kawamura (2000, apud LIBÂNIO, 2005), indicando o tratamento de ciclo completo como o mais adequado. Para confirmar a adequabilidade da técnica, a tratabilidade da água e a estimativa de parâmetros de projeto, devem ser elaborados ensaios em unidades piloto.

Com relação à abordagem utilizada neste trabalho, 
algumas considerações devem ser feitas. Foram considerados apenas alguns parâmetros físico-químicos e biológicos dentre os diversos prescritos no padrão de potabilidade. Parâmetros como Escherichia coli e algas, frequentemente associados à contaminação por esgotos domésticos e cianotoxinas não foram contemplados. Além disso, não foi avaliada a disponibilidade hídrica do manancial em termos quantitativos.

\section{Conclusões}

A caracterização das águas do Ribeirão Caladinho, afluente do Rio Piracicaba, tributário do Rio Doce, Minas Gerais, demonstrou a necessidade de ações de proteção do manancial, principalmente em relação à nascente, sendo constatada deterioração significativa da qualidade da água com o aumento da distância da nascente. Tal aspecto sugeriu que o aproveitamento do recurso hídrico exige que a captação de água seja feita em ponto mais próximo da nascente, onde a qualidade da água é melhor.

Destaca-se que não foi observada variabilidade significativa na qualidade da água entre os períodos seco e chuvoso. Já a correlação foi significativa entre todos os parâmetros avaliados, exceto para a temperatura da água, o que permite a exclusão de determinados parâmetros do monitoramento para simplificação do processo.

A técnica de tratamento mais indicada é a de ciclo completo, compreendendo as etapas de coagulação, floculação, decantação ou flotação, filtração, desinfecção, correção de pH e fluoretação. Todavia, devem ser elaborados ensaios em unidades piloto para confirmar a adequabilidade da técnica, a tratabilidade da água e a estimativa de parâmetros de projeto.

Este trabalho apresentou resultados que devem ser tomados como um estudo exploratório para guiar o desenvolvimento de estudos mais específicos, mas que carrega em si métodos aplicáveis a outras situações com o objetivo de fornecer uma referência acerca do potencial dos mananciais para o abastecimento humano.

\section{Referências}

ABNT. Associação Brasileira de Normas Técnicas. NBR 12216: Projeto de estação de tratamento de água para abastecimento público. Rio de Janeiro, 1992.

APHA. American Public Health Association. Standard Methods for the Examination of Water and Wastewater. 21. ed. Washington, D.C.: American Public Health Association, 2005.

AZEVEDO, L. G. T; PORTO, R. L. L; PORTO, M. Sistema de Apoio a decisão para o gerenciamento integrado de quantidade e qualidade da água: Metodologia e estudo de caso. Revista Brasileira de Recursos Hídricos, v. 3, n. 1, p. 21-51, 1998.

BABATUNDE, A. O; ZHAO, Y. Q. Constructive Approaches toward Water Treatment Works Sludge Management: An International Review of Beneficial Reuses. Journal of Science and Technology, v. 37, n. 2, p. 129-164, 2007.

BERTOLO, R. A.; MARCOLAN, L. N. O; BOUROTTE, C. Relações água-rocha e a hidrogeoquímica do cromo na água subterrânea de poços de monitoramento multiníveis de Urânia., SP, Brasil. Geologia USP. Série Científica, v. 9, n. 2, p. 47-62, 2009.

BRASIL. Ministério da Saúde. Portaria no 2.914, de 12 de dezembro de 2011. Dispõe sobre os procedimentos de controle e de vigilância da qualidade da água para consumo humano e seu padrão de potabilidade. Diário Oficial da União. Brasília-DF, 14 dez. 2011.

BRASIL. Conselho Nacional de Meio Ambiente. Resolução CONAMA no 357, de 17 de março de 2005. Dispõe sobre a classificação dos corpos de água e diretrizes ambientais para o seu enquadramento, bem como estabelece as condições e padrões de lançamento de efluentes, e dá outras providências. Diário Oficial da União. Brasília-DF, 2005.

HELLER, L. Concepção de instalações para o abastecimento de água. In: HELLER, L.; PÁDUA, V. L. (Org.). Abastecimento de água para consumo humano. Belo Horizonte: UFMG, 2006.

IBGE. Instituto Brasileiro de Geografia e Estatística. Cidades. Disponível em: <http://www.ibge.gov.br/ cidadesat>. Acesso em: 17 jul. 2012.

IGA. Instituto de Geociências Aplicadas. Secretaria de Estado de Ciência, Tecnologia e Ensino Superior (SECTES). Disponível em:

$<$ http://licht.io.inf.br/mg mapas/mapa/cgi/iga comeco1024.htm>. Acesso em: 15 jul. 2012.

KAWAMURA, S. Design of Basic Treatment Process Units. In: Integrated Design and Operation of Water Treatment Facilities. KAWAMURA, S. (Org.). 2. ed. EUA: John Wiley and Sons, Inc., 2000. p. 59-342.

LIBÂNIO, M. Fundamentos de Qualidade e Tratamento de Água. 2. ed. Campinas, SP: Átomo, 2005. 444 p.

MINAS GERAIS. Comitê da Bacia Hidrográfica do Rio Piracicaba. Disponível em: <http://www. cbhpiracicabamg.org/>. Acesso em: 12 jul. 2012. 
PÁDUA, V. L. Introdução ao tratamento de água. In: HELLER, L.; PÁDUA, V. L. (Org.). Abastecimento de água para consumo humano. Belo Horizonte: UFMG, 2006. p. 517-568. Volume 1, Capítulo 12.

SABOGAL PAZ, L. P ; Di Bernardo, L. Seleção de Tecnologias de Tratamento de Água em Função do Tratamento, Aproveitamento e Disposição dos Resíduos Gerados nas ETAs. Revista AIDIS de Ingeniería y Ciencias Ambientales, v. 1, p. 1-20, 2007.

STATSOFT, Inc.(versão 8.0) [Programa de computador]. Tulsa, USA: Statsoft, Inc., 2007. 